\title{
Actividades extraterritoriales represivas de la Armada Argentina durante la última dictadura civil-militar de Seguridad Nacional (1976-1983)
}

Melisa Slatman*

Resumen: El objetivo de este artículo es repasar las actividades represivas extraterritoriales de la Armada Argentina durante la última dictadura civil-militar de Seguridad Nacional en Argentina (1976-1983). Se explican, primero, las características del entramado institucional del Estado Terrorista Argentino y el lugar que cupo a la Armada en el mismo. Se analiza, en segundo lugar, el proceso de constitución, autonomización dentro de la estructura orgánica de la Armada y fin de ese proceso del Grupo de Tareas 3.3 de la Armada Argentina. Este Grupo de Tareas fue responsable de la gestión de uno de los mayores Centros Clandestinos de Detención argentinos: la Escuela de Mecánica de la Armada. Por último, se analiza la evolución de las actividades represivas extraterritoriales de este Grupo de Tareas.

Palabras clave: Armada Argentina. Dictadura. Actividades represivas extraterritoriales.

* Graduada en Historia por la Facultad de Filosofía y Letras de la Universidad de Buenos Aires. Es becaria doctoral del Consejo Nacional de Investigaciones Científicas y Tecnológicas (CONICET) y miembro del proyecto UBA Ciencia y Técnica (UBACyT). 


\section{Introducción}

El concepto “Operación Cóndor" es producto de un proceso de construcción social de conocimiento, que no siempre se apoyó en evidencia empírica. Su desarrollo tuvo que ver con la necesidad de vincular unos pocos indicios fácticos a la necesidad de denominar, para poder denunciar, el hecho de que en varios casos de desaparición de extranjeros en alguno de los países del Cono Sur, habían intervenido fuerzas represivas de otros países de manera coordinada. (SLATMAN, 2012). Aunque en la actualidad existe una cantidad, mayor pero aún limitada, de rastros acumulados procedentes de repositorios documentales de varios países, realmente se sabe poco sobre lo que fue realmente esa Operación. Esta situación llega al extremo de que ni siquiera hay acuerdo entre los analistas sobre si debe denominarse "operación", "sistema" o "plan".

En relación con lo anterior, es posible extraer información sobre la Operación Cóndor de las colecciones de documentos desclasificados por el Departamento de Estado de los Estados Unidos de Norteamérica. Esta documentación, no obstante, presenta límites: no son documentos de gestión de la represión, sino documentos construidos por actores y observadores que intentaban explicar lo que era esta operación. Esto, primero, para interceder ante las dictaduras de la región ante la violación de varios principios del derecho internacional, como la devolución forzada de refugiados; luego, para crear un marco cognitivo para el asesinato del ex canciller de la Unidad Popular Orlando Letelier en Washington en septiembre de 1977 y también para garantizar la hegemonía estadounidense en la región, por medio del establecimiento de relaciones unilaterales con los países. Estos documentos fueron producidos por organismos gubernamentales de diferente carácter (servicio exterior, justicia, defensa, organismos de inteligencia, etc.) y la información que contienen fue producida de manera acumulativa, dando lugar a una narración lineal y en líneas generales carente de contradicciones. Más aún, es mucho lo que dicen sobre los intereses norteamericanos en la región, pero poco sobre los procesos transnacionales, regionales y locales de los países del Cono Sur. 
Por otra parte, una cantidad limitada de documentos de gestión de la represión fue recuperada de diferentes archivos de la represión en el Cono Sur (CATELA; JELIN, 2002). Son documentos que no tenían por finalidad explicar lo que era la coordinación represiva, sino que registraron a las coordinaciones represivas en funcionamiento. Estos documentos dan cuenta de operaciones represivas coordinadas (asesinatos, secuestros, repatriaciones ilegales, campañas de acción psicológicas) y reuniones, conferencias y acuerdos bilaterales o multilaterales entre diferentes organismos represivos de la región y no necesariamente pueden relacionarse con la idea de "Operación Cóndor", hasta tanto no se pueda afirmar cabalmente qué fue esta operación.

Para sintetizar, entonces, el concepto “Operación Cóndor” se construyó sobre bases endebles. ${ }^{1}$ Esto lleva a la necesidad de volver a pensar, desde otra perspectiva, la investigación sobre las coordinaciones represivas. Otro enfoque del problema a partir de la información disponible implica, en la perspectiva de esta investigación, primero, pensar a las coordinaciones represivas en un plazo más largo que el que clásicamente se propone, entre noviembre de 1975 y 1978 a 1980 dependiendo del analista (DINGES, 2004; MCSHERRY, 2005). Segundo, pensar a las coordinaciones represivas como parte de un proceso histórico con una génesis, una fase de aceleración no carente de contradicciones y una fase de crisis. Y, por último, pensar este proceso histórico de coordinaciones represivas como un proceso múltiple, variado y de ninguna manera lineal. Esto se asocia con el hecho de que en cada uno de los países de la región, por tomar una unidad de análisis, coexistieron diferentes niveles de coordinación con organismos de otros países, que a veces eran paralelos, a veces conflictivos entre si, y otras veces eran cooperativos.

El objetivo de este trabajo es presentar las características generales de las actividades extraterritoriales represivas de la Armada Argentina (Fuerza Naval) durante la última dictadura cívico-militar en Argentina (1976-1983). Entre estas actividades represivas extraterritoriales se encuentran algunas asociadas al proceso histórico de coordinaciones represivas en el Cono Sur durante el último ciclo de dictaduras (1964-1991). Este recorte, se fundamenta en que, en el caso de las actividades represivas extraterritoriales de la Armada, 
ampliar el marco de observación a la lógica general de operaciones extraterritoriales permite una relectura de los operativos en el Cono Sur, y, de esta manera, permite profundizar en lo planteado más arriba sobre la multiplicidad de niveles de coordinación represiva en el interior de cada país.

\section{E1 Estado terrorista Argentino}

La pregunta sobre cómo Argentina en general y su Armada en particular, intervinieron en el proceso histórico de coordinaciones represivas, lleva a la necesidad de vincular lo que se conoce sobre la planificación y organización de la represión en el interior de Argentina, con la participación de diferentes organismos represivos en instancias de coordinación con sus pares regionales.

El período formativo del Estado Terrorista argentino comenzó en febrero de 1975, con el "Operativo Independencia" en la provincia argentina de Tucumán. ${ }^{2}$ En octubre de 1975, aprovechando el impacto social que produjo el ataque de la organización Montoneros a un cuartel militar en la provincia de Formosa, el Poder Ejecutivo Nacional aprobó los que se conocen como "decretos de aniquilamiento", que junto con órdenes y directivas emanadas de los altos mandos militares delinearon la forma de ejercicio de la represión durante la dictadura que comenzó en marzo de 1976. Estos decretos, número 2770, 2771 y $2772^{3}$ crearon, con el objeto de "reglar la intervención de las Fuerzas Armadas y en la ejecución de operaciones militares a los efectos de aniquilar el accionar de los elementos subversivos", un Consejo de Defensa y un Consejo de Seguridad Interior y extendieron a todo el país el "teatro de operaciones de la guerra contra la subversión”. El Consejo de Defensa, reunido a continuación, delineó la Directiva del Consejo de Defensa $N^{\circ}$ $1 / 75$, en la que se ordenó a las Fuerzas Armadas, de Seguridad y policiales su dedicación a la "aniquilación de la subversión". Se otorgó la responsabilidad primaria de la represión al Ejército, al que se subordinaron orgánicamente las Fuerzas de Seguridad y el Servicio Penitenciario; y funcionalmente, la Secretaría de Inteligencia del Estado. Se asignaron zonas prioritarias para el ejercicio de la 
represión (provincias de Tucumán, Córdoba, Santa Fe y las ciudades de Rosario, Capital Federal y La Plata). A las otras Fuerzas (Armada y Aérea) se les ordenó funciones secundarias de apoyo, pero se les otorgaron jurisdicciones de actuación.

El Ejército asumió aquella responsabilidad primaria y para ello, su comandante general impartió la Directiva 404/75 (Lucha contra la subversión). En 1976, el comandante en jefe del Ejército reformuló parcialmente esta directiva por medio de al Orden Parcial 405/76, redefiniendo las áreas prioritarias sobre las que se desarrollaría la represión. La represión que seguiría tras el golpe de Estado, fue definida por medio del Plan del Ejército (contribuyente al Plan de Seguridad Nacional), publicado en febrero del mismo año, en el que se hacía una evaluación concreta del "enemigo" a aniquilar y las vías para realizarlo a partir del golpe de Estado.

De manera que, luego del golpe de Estado, la represión en Argentina se ejecutó con una planificación centralizada y una forma de ejecución descentralizada (NOVARO; PALERMO, 2003), y la responsabilidad primaria en su desarrollo correspondió al Ejército. La planificación centralizada implicó que el teniente general del Ejército y su Estado Mayor generaron directivas bastante laxas sobre los objetivos generales de la represión. Y la ejecución descentralizada implicó la territorialización de la represión (CANELO, 2008), es decir, que el territorio nacional se dividió en "zonas de defensa", y estas se subdividieron, a su vez, en subzonas y áreas. Esta modalidad de organización territorial fue adaptada de las técnicas de guerra contrarrevolucionaria francesas y se había implementado desde 19724 (MAZZEI, 2002; MÁNTARAS, 2005), e implicó que cada comandante de cuerpo de Ejército, un general de división, pudiera decidir cómo llevar a cabo la represión en su territorio. Además, se crearon jurisdicciones represivas especiales para la Armada y para la Fuerza Aérea, a las que se le otorgaron subdivisiones territoriales ("áreas de defensa") en las cuales operaban de manera autónoma, coordinando y/o compitiendo con las otras fuerzas. Entonces, puede afirmarse que en tanto fueron cinco las “zonas de defensa” y, añadiendo además las áreas autónomas de la Armada y la Fuerza Aérea, en Argentina fueron siete las modalidades de ejecución de la represión 
(D'ANDREA MOHR, 1999; MIT'TELBACH; MIT'TELBACH, 2000; AGUILA, 2008; IZAGUIRRE, 2009).

Un segundo aspecto de esta planificación fue la centralidad otorgada a las unidades de inteligencia de las tres armas. En el caso del Ejército, a través del organigrama de su servicio de inteligencia. En cada una de las instancias territoriales arriba descritas cumplía funciones una unidad de inteligencia que era la responsable de la recopilación de información que se obtenía mediante el secuestro y la tortura. Esta información se centralizaba en el Batallón de Inteligencia 601, ubicado en la Capital Federal, que dependía del Servicio de Inteligencia del Ejército, que, a su vez, proveía información al jefe II del Ejército (Inteligencia). El jefe de inteligencia del Ejército tenía la responsabilidad de asesorar al teniente general del Ejército sobre la evolución del plan represivo. En paralelo actuaban el Servicio de Inteligencia Naval (y como se verá luego, también el Grupo de Tareas 3.3 de la Escuela Superior de Mecánica de la Armada) y el Servicio de Inteligencia de la Fuerza Aérea. Según la normativa vigente en la época, estos servicios de inteligencia debían coordinarse entre sí. Existieron instancias en las que esto sucedió, pero, no obstante, la puja de poder entre la Armada y el Ejército (CANELO, 2008), que es una de las características principales de la historia política de la dictadura en la Argentina, determinó que la coordinación no siempre funcionara, que la inteligencia se utilizara para debilitar a la otra Fuerza y que se produjeran instancias de competencia entre los servicios de inteligencia. Lo mismo sucedía en el interior de cada Fuerza (STEPAN, 1988; ANDERSEN, 1993).

Una última característica fue la especialización de cada Fuerza en la represión de determinadas organizaciones. A grandes rasgos se puede decir que la Armada y la Fuerza Aérea operaron contra organizaciones de origen peronista en las áreas donde tenían influencia, y el Ejército contra organizaciones de origen marxista en todas sus vertientes y contra el movimiento obrero organizado (organismos sindicales y agrupaciones de base). 


\section{La Armada Argentina durante la dictadura. Organiza- ción para la represión y el Grupo de Tareas (GT 3.3) de la Escuela Superior de Mecánica de la Armada}

Al tiempo que se dictaba la Directiva del Consejo de Defensa $N^{\circ}$ 1/75, la Armada Argentina ${ }^{5}$ adaptó su organigrama para participar en el plan represivo. El comandante en jefe de la Armada (Emilio Massera), emitió en el mismo mes de octubre, la Directiva Antisubversiva COAR 1/75 "S", que indicaba que la misión de la Armada sería operar en su jurisdicción y fuera de ella contra las organizaciones subversivas, para "detectarlas y aniquilarlas", e instruyó al Comando de Operaciones Navales (CON) para que emitiera un "plan estratégico operacional". El resultado fue el Plan de Capacidades CON N¹ "S"/ 75 Contribuyente Con La Directiva Antisubversiva COAR N¹/75 "S" (PLACINTARA/75) del 21 de noviembre de ese mismo año. Estos dos documentos definieron los objetivos y el modo de la participación de la Armada en la represión durante la dictadura. El "Plan Anual Naval" de 1976, determinó la preminencia de las actividades contrarrevolucionarias, especialmente en lo que hacía al uso de instalaciones, gastos, ocupación de personal y recursos de formación.

Las normativas antes mencionadas estipularon que a la organización administrativa (la cadena de mandos y responsabilidades orgánica de la Armada), que se ordenaba según el reglamento R.G-1 -007- “C”, Reglamento Orgánico de la Armada, del 14 de enero de 1975, se sobreimprimiera una cadena de mandos funcional a la "lucha contra la subversión” que se desprendía del PLACINTARA/75. Así, la Armada fue dividida en once Fuerzas de Tarea (FT), a las cuales se le asignaron dependencias edilicias, circunscripciones territoriales y misiones específicas. Estas FT que se subdividieron, a su vez, en Grupos de tareas (GT) y estas en Unidades de Tareas (UT) y en Elementos de Tareas (ET). Esta forma de organización no era nueva en la Armada, era la forma de organización funcional que debía adoptar en caso de conflicto bélico u otras circunstancias especiales y fue la forma de organización que adoptó también para su participación en la guerra por las islas Malvinas, por ejemplo. La coordinación de las FT quedó a cargo del Comando de Operaciones 
Navales, quien reportaba directamente al comandante en jefe de la Armada. De esta manera se creó una cadena de mandos paralela a la administrativa. Las FT, al funcionar dentro de dependencias en las que seguía vigente el organigrama administrativo, debían coordinar con los jefes de dichas dependencias el uso de los recursos.

La FT3 fue denominada “Agrupación Buenos Aires”. Según el PLACINTARA/75, su misión era la actividad ofensiva contra el "enemigo subversivo". Estaba organizada en diferentes GT, apostados en dependencias de la Armada, en la Capital Federal y provincia de Buenos Aires. Estos eran: el Batallón de Seguridad de la sede del Comando General de la Armada, la Base Aeronaval de Ezeiza, La Escuela Superior de Mecánica de la Armada, el Arsenal de Artillería de Marina de Zárate, los Apostaderos Navales de Buenos Aires y San Fernando, la Escuela Nacional de Náutica, el Arsenal Naval Azopardo y los demás organismos y dependencias de la Armada con asiento en la Capital Federal y el Gran Buenos Aires. Su comandante era el jefe de Operaciones del Estado Mayor General de la Armada ${ }^{6}$ y reportaba al Comando de Operaciones Navales.

Dentro de la FT 3 funcionó el GT 3.3 con base territorial en el predio la Escuela de Mecánica de la Armada. Y dentro de ella, funcionaron dos Unidades de Tareas, denominadas UT 3.3.1, (a cargo de tareas defensivas en el perímetro Avenida Congreso, Avenida de los Constituyentes, Avenida General Paz y el río de la Plata, en la Capital Federal) y UT 3.3.2 a cargo de las tareas ofensivas. La UT 3.3.2 no tenía una zona geográfica asignada y cuando operaba fuera de los límites defensivos indicados debía pedir autorización a la Jefatura de la Zona I (Comando del Primer Cuerpo del Ejército). En la práctica, por la propia evolución del GT y del proyecto político de Massera, los límites entre GT y UT se fueron diluyendo.

La afectada a las actividades desarrolladas en el Casino de Oficiales, donde se constituyó el Centro Clandestino de Detención, denominado "Selenio" por los represores, era la UT 3.3.27, donde estuvieron secuestradas, según el cálculo más preciso hasta el momento, cerca de 4250 personas (OLIVEIRA-CEZAR, 1988, p. 99). La UT 3.3.2 estaba compuesta por personal estable y personal rotativo, proveniente de otras unidades de la Armada. Estaba organizada en cuatro sectores: inteligencia, operaciones, logística y guardias. El 
sector de inteligencia era el encargado de planificar las operaciones, interrogar (y torturar) a las víctimas y decidir su destino final (que en la mayoría de los casos implicaba el asesinato y la desaparición física del cuerpo). Avanzado el período, desde comienzos de 1977, fue el sector que gestionó el llamado "proceso de recuperación”, por el que muchos detenidos fueron sometidos a trabajar en condiciones de esclavitud para los proyectos políticos de Massera y el sector de la Armada que lo apoyaba. El segundo sector, operaciones, se ocupaba del secuestro de las víctimas y el robo de sus pertenencias (desde bienes de uso diario hasta propiedades inmuebles). El tercero, que se encargaba de la logística de la U.T 3.3.2, era responsable por el aprovisionamiento de los grupos operativos y por el desarrollo y mantenimiento de la infraestructura del Centro Clandestino de Detenciones que gestionaba la U.T 3.3.2. A esto se sumaba un cuarto sector, el de los guardias, compuesto en su mayoría por alumnos de la ESMA, que se encargaban de la gestión cotidiana del Centro Clandestino de Detenciones: alimentación y traslado de las víctimas encapuchadas por el interior del recinto (FELD, 2010).

La historia del GT 3.3 es la historia de su proceso autonomización del organigrama administrativo de la Armada, pero también del organigrama funcional delineado en el PLACINTARA/75, y está íntimamente ligada con el auge y crisis del proyecto político del Almirante Emilio Massera (URIARTE, 1992; CANELO, 2008).

Un primer período se vincula con la subordinación del GT 3.3 al esquema de división territorial- jurisdiccional de la represión, cuando el GT que operaba en el Centro Clandestino de Detención "Selenio" en el predio de la Escuela Superior de Mecánica de la Armada, se encontraba subordinado al Servicio de Inteligencia Naval (SIN). Es decir, el GT era responsable del secuestro, el interrogatorio por medio de la tortura y de la gestión de los detenidos, pero lo que hacía a la planificación de los operativos a partir de la información obtenida era responsabilidad del (SIN).

El proyecto político de Massera comenzó siendo un proyecto político de un sector de la Armada. Su contenido evolucionó hacia un discurso aperturista, buscando transformarse en una alternativa a los ojos de la administración Carter, que propugnaba el establecimiento, en el Cono Sur, de democracias "viables", es decir, transiciones 
controladas del poder de los militares a los civiles, con el requisito de que estos nuevos gobiernos fueran anticomunistas. En el escenario interno, el proyecto de Massera era más ambicioso: buscaba lo que muchos antes que él: canalizar el apoyo peronista y convertir a su movimiento político en ciernes en un peronismo sin Perón. Hacia mediados de 1976 la Armada se dividió en dos fracciones: una, minoritaria pero con una gran cuota de poder, denominada "personalista", que buscaba aumentar el peso del almirante Massera dentro de la Junta Militar como una vía de crecimiento del poder de la Armada dentro del esquema general de reparto del poder entre las tres armas, base del acuerdo que dio lugar al golpe de Estado de Marzo; y otra fracción, mayoritaria, denominada "profesionalista", que también buscaba el aumento de la cuota de poder de la Armada, pero sin impulsar al Almirante Massera. La disputa con el Ejército fue acentuándose con el transcurso del tiempo, profundizándose con el desacelere del ritmo represivo, desde mediados de 1977 y más todavía, con la resolución de la disputa del "cuarto hombre"s a favor de Jorge Rafael Videla, quien, tras pasar a retiro a mediados de 1978 fue nombrado nuevamente presidente, lo cual implicó el fracaso de las aspiraciones de Massera.

En el interior de la ESMA esto se expresó en el apoyo de los miembros del GT a las aspiraciones personales de Massera y en la oposición de los efectivos del Servicio de Inteligencia Naval (OLIVEIRA-CEZAR, 1988). A comienzos de 1977, según declararon varios sobrevivientes, se produjo una "rebelión" del GT 3.3, que comenzó a negarse a informar los resultados de los interrogatorios a los miembros del SIN que operaban en el GT de la ESMA. Esta "rebelión" se correspondió en el tiempo con lo que se denominó "la caída de finanzas de Montoneros", es decir, el secuestro del sector de Montoneros que gestionaba sus intereses económicos, lo que deparó al GT ingentes recursos materiales ${ }^{9}$. El resultado de este enfrentamiento, que habría adquirido grandes dimensiones, fue la separación, en los hechos de las actividades del GT en relación con la realizada por el personal del SIN, que fue incentivada por Massera. Esto se materializó, entre otras cosas, en la división del espacio del Centro Clandestino de Detención en dos partes desiguales: al SIN correspondió lo que en la jerga de la ESMA se 
denominaba "Capuchita", que era el altillo del Casino de Oficiales, donde gestionaba a sus propios detenidos (aunque utilizaba el resto de las instalaciones) y al GT 3.3 se le otorgó el resto de los espa$\operatorname{cios}^{10}$ : "Capucha", el espacio de alojamiento de los detenidos; el "Sótano" que incluía salas de tortura, laboratorio fotográfico, sala de edición de audio y video, etc.; la "Pecera" que era el espacio donde se desarrollaban sus tareas aquellos sometidos al trabajo esclavo ("proceso de recuperación"). En relación con esto ultimo, en este segundo período se utilizó a los detenidos del GT 3.3 de la ESMA para los fines del proyecto político de Massera. Como se indicó más arriba, a la Armada correspondió la represión de las organizaciones de izquierda de origen peronista y más puntualmente, de Montoneros. En la ESMA estuvieron detenidos importantes cuadros de esa organización, incluso algunos cuadros de dirección, que fueron utilizados, a cambio de una promesa de sobrevida que no siempre se cumplió, para el desarrollo del proyecto político antes mencionado. Es decir, Massera y los Marinos del GT planificaron utilizar tanto los recursos materiales como los recursos humanos de Montoneros para desarrollar su proyecto político.

La situación descripta se mantuvo hasta el momento de pase a retiro de Massera (tercer período), en septiembre de 1978, que implicó además, la salida de la ESMA, entre septiembre de 1978 y principios de 1979 de quienes habían sido los principales gestores del Centro Clandestino de Detenciones, entre ellos, de su promotor principal, Eduardo ElTigre Acosta. La salida de Acosta permitió, por otra parte, la reunificación del GT con el personal del SIN, porque fue colocado al mando del GT de la ESMA Luis D'Imperio, quien a su vez era jefe de operaciones del Servicio de Inteligencia Naval. Este cambio de personajes no determinó el fin del funcionamiento de la ESMA como Centro Clandestino de Detenciones, ni de la esclavización de los detenidos, solo que ahora el funcionamiento del centro no tenía las motivaciones políticas que tuvo durante el período de Massera-Acosta. 


\section{Actividades del GT 3.3 y el SIN en el exterior}

Tipológicamente se puede afirmar la existencia de diferentes modalidades de actividades represivas extraterritoriales realizadas por el GT 3.3 de la Armada Argentina mediadas o no por relaciones de coordinación represiva organismos represivos de otros países.

Primero, operativos de recolección de información para la confección de inteligencia sobre activistas argentinos que se encontraran residiendo en el exterior del país. Estas actividades pudieron o no estar vinculadas con relaciones de coordinación represiva. Por ejemplo, Graciela Daleo, sobreviviente de la ESMA, relató que estando detenida

A nosotros nos hacen ver en una filmación para ver si lo reconocíamos... una filmación que estaban haciendo de un compañero en Montevideo y después resulto que era Rolando Pisarello, digamos, que recuerdo que era una filmación en blanco y negro de un compañero que andaba el 18 de Julio por una calle que entraba y salía en una galería y que se yo. Todo el mundo dijo "no lo conozco, no lo conozco, no lo conozco". Después, cuando lo secuestraron [nos dimos cuenta de] que, bueno, era el seguimiento que le estaban haciendo a Rolando. ${ }^{11}$

Segundo, operativos de repatriación forzada de exiliados secuestrados fuera del país. En la mayoría de los casos fueron operativos en los que se secuestró a militantes o ex militantes de la organización Montoneros. El más importante por su volumen fue el traslado de miembros de la Columna Oeste de Montoneros detenidos en Uruguay por el cuerpo de Fusileros Navales (FUSNA) en diciembre de 1977. Algunas de las víctimas de este operativo fueron repatriadas forzosamente: Oscar DeGregorio, Rosario Quiroga, Rolando Pisarello, María del Huerto Milessi y Jaime Dri. También fueron repatriadas las tres hijas de Rosario Quiroga, que estuvieron secuestradas en la ESMA por algunos días y fueron liberadas poco tiempo después. En el operativo fueron muertos Juan Alejandro Barry, secretario político del Partido Peronista Montonero 
y su mujer, Susana Beatriz Mata Freixas, quien, según los informes oficiales, ingirió una pastilla de cianuro para evitar ser detenida con vida. La hija de ambos fue mantenida secuestrada por las fuerzas represivas uruguayas y entregada luego a sus abuelos maternos ${ }^{12}$. También fueron detenidos otros individuos, que no eran militantes pero si simpatizantes de la organización: Miguel Angel Estrella, Luisana Beatriz Olivera Craizoz y Jaime Luis Brancony Lucero, quienes no fueron repatriados y fueron puestos a disposición de la justicia uruguaya, quedando detenidos en ese país (PRESIDENCIA DE LA REPÚBLICA ORIENTAL DEL URUGUAY, 2007; 2011).

Tercero, operativos para intentar asesinar a dirigentes de la organización Montoneros en el exterior. Durante la dictadura, México se convirtió en un espacio importante para el refugio de los exiliados latinoamericanos. En su capital llegaron a residir los cuadros más importantes de Montoneros (YANKELEVICH, 2009). Miembros del GT viajaron a México en mayo de $1979^{13}$ según relata Adriana Marcus, sobreviviente del centro clandestino de la ESMA, que fue obligada a acompañar al Teniente de Corbeta Alberto Gonzalez Menotti (a) "Gato" y al Teniente de Navío Adolfo Donda Tigel. Adriana Marcus fue provista con un juego de documentación falsa, que había sido elaborada por detenidos sometidos a régimen de trabajo esclavo. Viajaron en una línea aérea común y tras hacer escala en Panamá arribaron a México, donde tomaron un avión a otro pueblo. Afirmó Adriana Marcus que

[...] ellos aparentemente tenían entrevistas con algunos contactos que puedo imaginar que también eran milicos, para conseguir armas o algo por el estilo. Tengo ese recuerdo, que ya no sé si corresponde a lo que me imaginaba o a lo que alcancé a escuchar (ACTIS, ALDINI et al., 2001, p. 176).

Luego de dos días volvieron al Distrito Federal. Según estima Marcus, a ella la habrían llevado a México para aparentar, "para que no fuera evidente que se trataba de un grupo de inteligencia”. De su estadía en el Distrito Federal rescata la siguiente vivencia: 
Adriana: En un determinado momento estábamos en una disquería mirando discos y casetes y de golpe uno de ellos entró de la calle muy agitado.

Munú: ¿'Te acordás si andaban armados?

Adriana: Nunca lo supe. Parecía que había una cita. Uno estaba adentro de la disquería y el otro afuera. Teníamos que ir a algún lugar.

Munú: ¡Ah!

Adriana: En una de esas Gerónimo [Donda] me agarró del brazo como para arrastrarme hacia afuera y llevarme con el. Yo logré soltarme y me puse a hablar con el tipo del local. Ellos salieron corriendo, yo me quedé ahí y al rato volvieron reprochándose mutuamente que se hubieran escapado.

Munú: ¡Ah!

Elisa: ¿Quién se les escapó?

Adriana: No lo sé. Alguien con quien ellos tendrían que entrevistarse. Se ve que estaban esperando a alguien en ese lugar (ACTIS; ALDINI et al., 2001, p. 178-179).

El represor Adolfo Miguel Donda reconoció haber realizado este viaje. Durante el debate oral realizado en el marco de la causa ESMA aceptó que "en ese momento me encontraba en la Ciudad de México, hecho corroborado por la declaración de una señora que no me acuerdo en este momento el apellido, el nombre de guerra era "Nuchi"... estuvimos un mes en la Ciudad de México..." Durante el debate negó el proyecto de los asesinatos, pero explicó que debieron viajar a esa ciudad para recabar información, ya que en ese momento México era, según sus palabras, "un santuario de los terroristas del mundo" y recordó que fue acompañado por el teniente Gonzalez y que la orden para realizar este operativo había sido dada por el Tigre Acosta y Luis D’Imperio. A este ultimo reportó los resultados de la misión (Tribunal Oral Federal En Lo Criminal Y Correccional Número 5, 28 de diciembre de 2011, p. 76).

Operativos en esta misma línea fueron el intento de secuestro, en 1977, del dirigente de la Confederación General Económica Julio Broner en Venezuela; el intento de secuestro de Jaime Dri en Paraguay, quien se había fugado en la frontera Argentino-Paraguaya 
donde lo habían enviado para señalar a militantes Montoneros que intentaran ingresar al país, en julio de 1978; un nuevo operativo para asesinar a Jaime Dri en Roma en marzo de 1979; el intento de asesinato del ex diputado peronista Armando Croatto en Madrid en septiembre de 1978. Otros operativos similares fueron el intento de asesinato de Adriana Lesgart en Bélgica y del sindicalista Gonzalo Chávez en Suiza.

Cuarto, operativos de acción psicológica con el objetivo de desprestigiar a los exiliados y principalmente, a los de la organización Montoneros, vinculados o no con la repatriación forzada de miembros de esa organización que se encontraban en el exilio y su posterior desaparición. Un caso ejemplar, en este sentido, fue el de la operación que se realizó tras el secuestro de Alejandrina Barry. Este caso se dio en el marco del operativo de secuestro de los Montoneros en Uruguay a fines de 1977 descritos arriba. Unas semanas después del operativo, cuando había trascendido la noticia a los medios uruguayos y argentinos, la niña fue fotografiada en la casa en la que había sido encontrada, rodeada de armas, con el objeto de crear una visión negativa en la sociedad argentina acerca de los Montoneros y de la relación que estos tenían con sus hijos ${ }^{14}$.

El caso de Thelma Jara de Cabezas es otro ejemplo. Jara de Cabezas fue secuestrada el 30 de abril de 1979 en la Capital Federal. ${ }^{15}$ Madre de un desaparecido en 1976 y de un militante montonero exiliado en México, fue llevada a la ESMA donde los marinos la mantuvieron cautiva. Antes, a consecuencia de la desaparición de su hijo, había tomado contacto y participado de actividades de las que luego serían conocidas como las Madres de Plaza de Mayo y también de Familiares de Detenidos-Desaparecidos. Entre enero y febrero de 1979 había viajado a México a reclamar ante los obispos del Consejo Episcopal Americano y también se vinculó con la dirigencia del Movimiento Peronista Montonero, habiendo participado de una reunión secreta en Roma. Según la entrevista que brindó a Miguel Bonasso, el GT 3.3/2 venía siguiéndole los pasos desde antes de viajar. Como afirmó Jara de Cabezas a Bonasso, el Prefecto Héctor Febres (a. "Gordo Daniel" o "Daniel) 
Le comentó que la estuvo campaneando en Ezeiza el día de su partida. Viajó con ella a México en el mismo avión, la siguió en el DF mexicano cuando se encontró con su hijo y su nuera; los perdió en un astuto cambio de auto y volvió a encontrarla en Roma cuando el mismo se "cruzó" con la patota de Firmenich. No le dirá, claro, lo que el autor de esta nota sabrá muchos años después: que Daniel viajó a Roma con otros miembros de la verdadera patota para asesinar con dardos envenenados a Jaime Dri, que, en 1978 se había escapado de la ESMA (BONASSO, 1984).

En el marco de su secuestro, Jara de Cabezas fue también víctima de una campaña de acción psicológica que contenía elementos de coordinación represiva. El Teniente de Fragata Ricardo Miguel Cavallo (a. "Marcelo" o "Sérpico"), la amenazó de muerte para que colaborara en la realización de una entrevista en la que ella debía afirmar su desengaño con los Montoneros y los organismos de Derechos Humanos, y para relatar que ella no se hallaba desaparecida, sino que, perseguida por la organización Montoneros, se había refugiado en el Uruguay, donde la auxiliaban familiares suyos. Esto en el marco de una campaña internacional por su liberación. Además, fue obligada a enviar cartas a organismos de derechos humanos, personalidades internacionales y hasta a funcionarios gubernamentales vinculados con el Ejército que desmintieran su secuestro. Relata Bonasso que

La operación fue redondeada con otros "trabajos". Un día la sacaron a la Panamericana y le tomaron fotos "producidas", con un background de carteles comerciales uruguayos para fingir que estaba en Montevideo. Luego "la producción” se incrementaría y la llevarían al Uruguay [...] Cavallo (en ese entonces "Marcelo") la llevó dos veces a Montevideo para simular que vivía allí por miedo a la supuesta venganza de los Montoneros. Él se ocupaba de todos los trámites [...] En Carrasco los esperó dos veces un misterioso sujeto de civil que hizo pasar sin control al marino y a la mujer de pañoleta $\mathrm{y}$ anteojos oscuros que viajaba con un pasaporte a nombre de 
Magdalena Manuela Blanco, confeccionado en el sótano de la ESMA. Las dos veces fueron y volvieron en el día. En una ocasión debían verse con unos periodistas, que finalmente no llegaron. A la segunda reunión, realizada en un departamento conseguido por el misterioso uruguayo, asistió un periodista de World News y dos marinos del Centro Piloto de París. La nota saldría rebotada en un cable de Télam y en la célebre Revista Para Tí. ${ }^{16}$

Quinto, operativos de infiltración en las comunidades de exiliados con el fin de desalentar las denuncias contra la dictadura en general y contra la Armada en particular. Un ejemplo de esto fue la infiltración del marino Alfredo Astiz en la comunidad de exiliados argentinos en París a fines de 1977. Infiltrado con el nombre de Alberto Escudero, Astiz participó de algunas actividades del Comité Argentino de Información y Solidaridad (CAIS) y otros organismos del exilio argentino en París, siendo reconocido por sus militantes y denunciado públicamente (ROSENBERG, 1991; FRANCO, 2008). El marco de este operativo fue el Centro Piloto de París, organismo vinculado con la Embajada Argentina en Francia que tenía como objetivo principal la realización de campañas de acción psicológica para desarmar la denuncia de la dictadura que llevaban a cabo los exiliados en Europa y también para fortalecer la imagen exterior de la Argentina (y principalemente del Almirante Massera) pero que sirvió de base permanente para las operaciones de los marinos en Europa.

En cuanto a las motivaciones para estos diferentes tipos de operativos, fueron varios los impulsos que llevaron al GT 3.3 a realizarlos: la ideología que orientó la represión y las actividades que de ella emergieron; la competencia por el poder con el Ejército, la búsqueda de beneficios materiales por medio de la apropiación de bienes de individuos y organizaciones derivados de las actividades represivas y la búsqueda de moderar el efecto de las actividades de denuncia de los exiliados argentinos en el exterior y particularmente, y en particular, el efecto de la denuncia de los sobrevivientes de este Centro Clandestino de Detenciones.

Los tres períodos enunciados de desarrollo del GT 3.3 tuvieron un correlato en la evolución de las actividades extraterritoriales. 
Durante el primer período, no se registraron actividades extraterritoriales del GT 3.3, cuando se encontraba bajo la órbita del SIN.

Los cinco tipos de acciones descritas arriba fueron desarrollados durante el período de autonomización del GT 3.3 y se vinculan con los motivos antedichos. Es importante señalar que salvo en el caso de la repatriación forzada de los Montoneros desde Uruguay, el resto de los operativos resultaron fallidos y los testimonios coinciden en que se trató de puestas en escena tendientes a justificar los costosos viajes de campaña de Massera alrededor del globo (OLIVEIRA-CEZAR, 1988, p. 211). En relación con la disputa entre el G.T 3.3 y el SIN, característica de esta etapa, es muy pequeño el registro de actividades extraterritoriales del SIN: un operativo de repatriación forzada de uno de los miembros fundadores de Montoneros desde Perú en abril de 1977, en el que habría participado el jefe operativo del SIN Luis D'Imperio, aunque hay versiones que atribuyen este operativo al Ejército (UCEDA, 2004). Otro caso, el de la repatriación forzada de tres argentinos y dos uruguayos desde Paraguay en marzo de 1977, está mejor documentado, y se aprecia que las tareas de inteligencia y resguardo de las victimas trasladadas estuvo a cargo de personal de la SIDE. D'Imperio aparece implicado en el traslado, como piloto del avión que los trajo a la Argentina y los detenidos fueron alojados en un Centro Clandestino de Detención que no correspondía a la orbita de la Armada. Fue probado con posterioridad que el avión que se utilizó en este traslado era el avión asignado a los traslados particulares del comandante de la Armada, Emilio Massera ${ }^{17}$. Durante el tercer período se da una continuidad en la práctica de las acciones extraterritoriales, pero ahora sin el marco de las actividades políticas de Massera. En este sentido, las acciones parecen haberse centrado más que antes en la represión política y los intereses económicos.

\section{Consideraciones finales}

En varios aspectos, los estudios de las coordinaciones represivas en el Cono Sur durante el último ciclo de dictaduras desde la perspectiva del concepto de "Operación Cóndor" pueden resultar

Anos 90, Porto Alegre, v. 19, n. 35, p. 237-260, jul. 2012 
limitados y limitantes. Una nueva perspectiva de análisis sobre las coordinaciones represivas debe incluir nuevas periodizaciones, otras escalas de observación y vincular los entramados internos de los Estados Terroristas con las coordinaciones represivas.

La forma de la participación del Estado Terrorista argentino en las coordinaciones represivas de aquel ciclo de dictaduras estuvo íntimamente vinculada con el modo de organización de la represión interna. La autonomía de cada una de las Fuerzas Armadas en el interior del país se expresó también en su accionar extraterritorial con o sin coordinación represiva. Y en este nivel replicaron también los conflictos que se generaron entre las Armas producto de esta forma de organización de la represión.

Es por eso que, para analizar la participación de cada una de las Fuerzas Armadas argentinas en las coordinaciones represivas es necesario analizar sus historias internas y el arco general de sus actividades extraterritoriales. Este marco permite dar significación a las actividades extraterritoriales con o sin coordinación represiva más allá de la forma que estas actividades hayan tomado.

En el caso de la Armada Argentina, el desarrollo su forma de organización específica para la represión; las relaciones internas del Arma y las relaciones con las otras Armas y la evolución de ciertos proyectos políticos en su interior, moldearon la forma específica de las actividades extraterritoriales de uno de sus componentes, el GT 3.3, que tenía como sede de operaciones a la Escuela Superior de Mecánica de la Armada. El estudio de estos elementos y procesos históricos da lugar a una resignificación histórica de las actividades represivas extraterritoriales del GT 3.3 y permiten ir más allá de la descripción fenoménica de las actividades represivas en el exterior.

Así, la puesta en relación del entramado represivo interno y la evolución política de los actores de la dictadura permiten dar significado e historicidad a las diferentes estrategias represivas desarrolladas en el exterior del país. 


\section{OFFSHORE REPRESIVE ACTIVITIES OF ARGENTINA NAVY DUR- ING THE LAST NATIONAL SECURITY DICTATORSHIP (1976-1983)}

Abstract: The aim of this paper is to review the extraterritorial repressive activities of the Argentine Navy, during the civil-military dictatorship of National Security in Argentina (1976-1983). It is explained, first, the characteristics of the institutional framework of the Argentine Terrorist State, and the place of the Navy in it. It is analyzed, secondly, the emergence, empowerment within the organizational structure and crisis of the Navy Task Group 3.3 of the Argentine Navy. This Task Force was responsible for the management of one of the largest Argentine Clandestine Detention Centers: the "Escuela de Mecánica de la Armada". Finally, it is analyzed the evolution of extraterritorial repressive activities of this Task Force.

Keywords: Argentinean Navy. Dictatorship. Offshore represive activities.

\section{Notas}

${ }^{1}$ Vania Markarian llegó a conclusiones similares a partir del análisis del caso uruguayo (MARKARIAN, 2011)

${ }^{2} \mathrm{El}$ Operativo Independencia fue el primer momento de intervención plena de las Fuerzas Armadas en la represión. Durante este operativo, que transcurrió entre febrero y diciembre de 1975, se desarrollaron los primeros centros clandestinos de detención y tuvo como saldo 680 "bajas", entre muertos y desaparecidos.

3 SEGURIDAD NACIONAL. Consejo de Seguridad Interna. Consejo de Defensa. Competencias y atribuciones. Convenio con las provincias. Operaciones militares y de seguridad. Decreto 2770 (Bs As. 06/10/1975); Decreto 2771 (Bs. As. 06/10/1975); Decreto 2772 (Bs. As. 06/10/1975). Boletín Oficial de la República Argentina $\mathrm{N}^{\circ} 23276,4 / 11 / 1975$

${ }^{4}$ A través del Plan del Ejército para el marco interno, emitido por el general Alejandro Agustín Lanusse en 1972. Ejército Argentino, Plan del Ejército para el marco interno (PE-MI-72), 1972. Citado por (MÁNTARAS, 2005)

${ }^{5}$ En la descripción que sigue se utilizaron los documentos citados en el texto y dos documentos que surgieron del juicio por la violación de los derechos humanos en la Escuela Superior de Mecánica de la Armada: (TRIBUNAL ORAL FEDERAL EN LO CRIMINAL Y CORRECCIONAL NÚMERO 5, 28 de diciembre de 2011; UNIDAD FISCAL DE ASISTENCIA PARA CAUSAS POR VIOLACIONES A LOS DERECHOS HUMANOS DURANTE EL TERRORISMO DE ESTADO, 2011) 


\section{Melisa Slatman}

${ }^{6}$ Durante el período de la dictadura, los responsables de la FT 3 fueron Oscar Montes, Manuel Jacinto García Tallada, Julio Antonio Torti, Carlos Humberto Bonino, Humberto Barbuzzi, Rubén Oscar Franco, Juan José Lombardo, Leopoldo Suárez Del Cerro, Edgardo Otero, Guillermo Costa, y Mario Palet.

${ }^{7}$ Según relato de la declaración indagatoria de Miguel Angel Donda ante el Tribunal Oral Federal en lo Criminal y Correccional Número 5 durante el debate oral por la causa ESMA. En (TRIBUNAL ORAL FEDERAL EN LO CRIMINAL Y CORRECCIONAL NÚMERO 5, 28 de diciembre de 2011, p. 61-77)

${ }^{8} \mathrm{Al}$ momento de la toma del poder, entre los acuerdos efectuados por las tres armas, estuvo el de división tripartita del poder, que implicó una división de los espacios de gestión legales que idealmente sería del treinta y tres por ciento para cada una de las armas, pero en la cual el Ejército terminó teniendo una cuota mayor. Otro de los acuerdos fue el del "cuarto hombre": el país sería gobernado según un esquema semi republicano, con un presidente que respondería a una junta militar compuesta por un miembro de cada una de las Fuerzas. Ese cuarto hombre podía o no ser miembro de las Fuerzas Armadas, pero no podía ser un oficial activo. Hasta mediados de 1978 el Ejército hizo caso omiso de ese acuerdo, concentrando en la figura de Videla la presidencia y la representación del Ejército en la Junta Militar. A mediados de 1978 Videla pasó a retiro, dejando su lugar en la Junta a Roberto Viola y pasando a ocupar el lugar del "cuarto hombre". ${ }^{9}$ Aquí vale aclarar que esta organización, producto de varios operativos importantes, entre ellos el secuestro de los hermanos Juan y Jorge Born, en 1974, que había dejado como saldo a la organización entre cuarenta y sesenta millones de dólares.

${ }^{10}$ Entrevista a Pilar Calveiro, realizada por la autora, Buenos Aires.

${ }^{11}$ Entrevista a Graciela Daleo, Buenos Aires. Realizada por la autora. Rolando Pisarello fue detenido en Uruguay el 15 de diciembre de 1977 y trasladado a la ESMA el 22 de diciembre del mismo año

${ }^{12}$ Aunque su hija Alejandrina duda de esta versión oficial. Entrevista con Alejandrina Barry, Buenos Aires. Realizada por la autora

${ }^{13}$ El Ejército, por su parte, había intentado una operación semejante en 1978 con el objeto de asesinar a la cúpula de esta organización. Véase (OSORIO; FRANZBLAU, 2008; OSORIO; ENAMONETA, 2009)

${ }^{14}$ Entrevista de la autora con Alejandrina Barry. Buenos Aires. Las notas, de diciembre de 1977 son "A ellos no les importa Alejandra", Revista Gente, 05/01/1978; "Los hijos del terror, Revista Somos, 30/12/1977 y "Esto también es terrorismo. Alejandra está sola”, Revista Para Ti, 16/01/1978

${ }^{15}$ (BONASSO, 04/09/2000)

16 (BONASSO, 04/09/2000) La nota en Para Ti fue publicada finalmente el 10 de septiembre de 1979 con el título "Habla la madre de un subversivo muerto". 
${ }^{17}$ Centro de Documentación y Archivo. 00008F 1742. Policía de Investigaciones. Departamento de Investigaciones. Asunción-Paraguay. "Memorando del Jefe de Investigaciones para su excelencia el Señor Presidente de la República”. 27 de mayo de 1977; Centro de Documentación y Archivo, Fotograma 0017 F1319. Sin título. 16 de mayo de 1977; Centro de Documentación y Archivo. Policía de Investigaciones. Departamento de Investigaciones. Asunción-Paraguay. Fotograma 0017F 1310. "Corresponde a la Ficha N 3854. José Nell”. Sin Fecha; Centro de Documentación y Archivo. Policía de Investigaciones. Departamento de Investigaciones. Asunción-Paraguay. "Resumen de las actividades de ICIA [inteligencia] días 5/6 de abril de 1977". Secreto. Sin fecha; Centro de Documentación y Archivo. 00008F 1742. Policía de Investigaciones. Departamento de Investigaciones. Asunción-Paraguay. "Memorando del Jefe de Investigaciones para su excelencia el Señor Presidente de la República”. 27 de mayo de 1977; Centro de Documentación y Archivo, Fotograma 0017 F1319. Sin título. 16 de mayo de 1977.

\section{Referencias}

ACTIS, Munú et al. Ese infierno: conversaciones de cinco mujeres sobrevivientes de la ESMA. Buenos Aires: Editorial Sudamericana, 2001.

AGUILA, Gabriela. Dictadura, represión y sociedad en Rosario, 1976-1983: un estudio sobre la represión y los comportamientos y actitudes sociales en dictadura. Buenos Aires, Argentina: Prometeo Libros, 2008.

ANDERSEN, Martin Edwin. Dossier secreto: Argentina's Desaparecidos and the myth of the "Dirty War". Boulder: Westview Press, 1993.

BONASSO, Miguel. La increible historia de Thelma Jara de Cabezas en manos del represor Cavallo. Un viaje por los abismos de la ESMA. Página/12. Buenos Aires 04 set. 2000. - Recuerdo de la muerte. México: Ediciones Era, 1984.

CANELO, Paula. El proceso en su laberinto: la interna militar de Videla a Bignone. Buenos Aires: Prometeo, 2008.

CATELA, Ludmila da Silva; JELIN, Elizabeth (Eds.). Los archivos de la represión: documentos, memoria y verdad. Madrid: Siglo Veintiuno de España Editoresed, 2002.

D’ANDREA MOHR, José Luis. Memoria debida. Buenos Aires, Argentina: Colihue, 1999. 


\section{Melisa Slatman}

DINGES, John. Operación Cóndor, Una década de terrorismo internacional en el Cono Sur. Santiago de Chile: Ediciones B, 2004.

FELD, Claudia. El centro clandestino de detención y su frontera. Algunas notas sobre testimonios de la experiencia de cautiverio en la ESMA. In: LA FUNDACIÓN HEINRICH BÖL CONO SUR (Ed.). Recordar para pensar. Memoria para la democracia. La elaboración del pasado reciente en América Latina. Santiago de Chile: Ediciones Böll Cono Sur, 2010.

FRANCO, Marina. El exilio: argentinos en Francia durante la dictadura. Buenos Aires: Siglo Veintiuno Editores, 2008.

GILLESPIE, Richard. Soldados de Perón. Historia crítica sobre los Montoneros. Buenos Aires: Sudamericana, 2008

IZAGUIRRE, Inés. Lucha de clases, guerra civily genocidio en la Argentina 1973-1983: antecedentes, desarrollo, complicidades. 1. Buenos Aires: Eudeba, 2009.

MÁNTARAS, Mirta. Genocidio en Argentina. Buenos Aires: M. Mántaras, 2005.

MARKARIAN, Vania. Una mirada desde Uruguay a la coordinación represiva regional, 1973-1984. In: BOHASLAVSKY, Ernesto et al. (Ed.). Problemas de historia reciente en el Cono Sur. Prometeo y UNGS, v. 1, 2011. p. 265-286.

MAZZEI, Daniel H. La misión militar francesa en la Escuela Superior de Guerra y los orígenes de la Guerra Sucia, 1957-1961. Revista de Ciencias Sociales. Universidad Nacional de Quilmes, v. 13, n. Diciembre, p. 105-137, 2002.

MCSHERRY, J. Patrice. Predatory states: Operation Condor and covert war in Latin America. Lanham, MD: Rowman \& Littlefield Publishers, Inc., 2005.

MIT'TELBACH, Frederico; MITTELBACH, Jorge Luis. Sobre áreas y tumbas: informe sobre desaparecedores. Buenos Aires: Editorial Sudamericana, 2000.

NOVARO, Marcos; PALERMO, Vicente. La dictadura militar, 1976-1983: del golpe de estado a la restauración democrática. Buenos Aires: Paidós, 2003.

OLIVEIRA-CEZAR, María. Un modelo contrarrevolucionario en Argentina. El Grupo de Tareas de la Escuela de Mecánica de la Armada (Mimeo). París, 1988.

OSORIO, Carlos A.; ENAMONETA, Marianna. Operación México: Programa argentino de rendición extraordinaria revelado por documentos desclasificados. NATIONAL SECURITY ARCHIVE. In: National Security Archive Electronic Briefing Book No. 300. G. W. U. Washington DC, 2009.

OSORIO, Carlos A.; FRANZBLAU, Jesse. National Security Archive Electronic Briefing Book Nº. 241, 1978: Operación Clandestina de la Inteligencia Militar Argentina en México. UNIVERSITY, N. S. A. - G. W. Washington D.C 2008.

Anos 90, Porto Alegre, v. 19, n. 35, p. 237-260, jul. 2012 
PRESIDENCIA DE LA REPÚBLICA ORIENTAL DEL URUGUAY. Investigación Histórica sobre Detenidos Desaparecidos. En complimiento del Artículo $4^{\circ}$ de la ley 15.848. Montevideo: Presidencia de la República y Dirección Nacional de Impresiones y Publicaciones Oficiales, 2007.

. Actualización de la investigación histórica sobre detenidos desaparecidos, 2011.

ROSENBERG, Tina. Children of Cain: violence and the violent in Latin America. New York: Wm. Morrow, 1991.

SLATMAN, Melisa. Archivos de la represión y ciclos de producción de conocimiento social sobre la Operación Cóndor. In: Taller (Segunda Epoca), v. 1, n. 1, p. 41-58, 2012.

STEPAN, Alfred C. Rethinking military politics: Brazil and the Southern Cone. Princeton, N. J.: Princeton University Press, 1988.

TRIBUNAL ORAL FEDERAL EN LO CRIMINAL Y CORRECCIONAL NÚMERO 5. Sentencia causa "ESMA” Buenos Aires: 28 de diciembre de 2011.

UCEDA, Ricardo. Muerte en el Pentagonito: los cementerios secretos del Ejército Peruano. Bogotá: Planeta, 2004.

UNIDAD FISCAL DE ASISTENCIA PARA CAUSAS POR VIOLACIONES A LOS DERECHOS HUMANOS DURANTE EL TERRORISMO DE ESTADO. Alegato. Causa ESMA. Presentado ante el Tribunal Oral Federal $N^{\circ} 5$, leído durante los días 15, 16, 17, 23 y 24 de junio de 2011.

URIARTE, Claudio. Almirante Cero: biografía no autorizada de Emilio Eduardo Massera. Buenos Aires: Planeta, 1992.

YANKELEVICH, Pablo. Ráfagas de un exilio: argentinos en México, 1974-1983. México: Colegio de México, 2009.

Recebido em: 11/07/2012

Aprovado em: 10/09/2012 